Article

\title{
Estimating Reservoir Release Using Multi-Source Satellite Datasets and Hydrological Modeling Techniques
}

\author{
Youjiang Shen ${ }^{1} \mathbb{D}$, Dedi Liu ${ }^{1, *}$, Liguang Jiang ${ }^{2} \mathbb{D}$, Christian Tottrup ${ }^{3} \mathbb{D}$, Daniel Druce ${ }^{3}$ (D) Jiabo Yin ${ }^{1}$, \\ Karina Nielsen ${ }^{4}$, Peter Bauer-Gottwein ${ }^{5}$ iD, Jun Wang ${ }^{1}$ and Xin Zhao ${ }^{6}$
}

1 State Key Laboratory of Water Resources and Hydropower Engineering Science, Wuhan University, Wuhan 430072, China; yjshen@whu.edu.cn (Y.S.); jboyn@whu.edu.cn (J.Y.); wangjwd@whu.edu.cn (J.W.)

2 School of Environmental Science and Engineering, Southern University of Science and Technology, Shenzhen 518055, China; jianglg@sustech.edu.cn

3 DHI-GRAS, 2970 Horsholm, Denmark; cto@dhigroup.com (C.T.); dadr@dhigroup.com (D.D.)

4 DTU Space, National Space Institute, Technical University of Denmark, 2800 Kongens Lyngby, Denmark; karni@space.dtu.dk

5 Department of Environmental Engineering, Technical University of Denmark, 2800 Kongens Lyngby, Denmark; pbau@env.dtu.dk

6 Bureau of Hydrology, Changjiang Water Resources Commission, Wuhan 430010, China; waw130043@gmail.com

* Correspondence: dediliu@whu.edu.cn

\section{check for} updates

Citation: Shen, Y.; Liu, D.; Jiang, L.; Tøttrup, C.; Druce, D.; Yin, J.; Nielsen, K.; Bauer-Gottwein, P.; Wang, J.; Zhao, X. Estimating Reservoir Release Using MultiSource Satellite Datasets and Hydrological Modeling Techniques. Remote Sens. 2022, 14, 815. https:// doi.org/10.3390/rs14040815

Academic Editor: Giovanni Battista Chirico

Received: 6 January 2022

Accepted: 7 February 2022

Published: 9 February 2022

Publisher's Note: MDPI stays neutral with regard to jurisdictional claims in published maps and institutional affiliations.

Copyright: (C) 2022 by the authors. Licensee MDPI, Basel, Switzerland. This article is an open access article distributed under the terms and conditions of the Creative Commons Attribution (CC BY) license (https:// creativecommons.org/licenses/by/ $4.0 /)$.

\begin{abstract}
Reservoir release is an essential variable as it affects hydrological processes and water availability downstream. This study aims to estimate reservoir release using a satellite-based approach, specially focusing on the impacts of inflow simulations and reservoir water storage change (RWSC) on release estimates. Ten inflow simulations based on hydrological models and blending schemes are used in combination with three RWSC estimates based on two satellite-based approaches. A case study is performed at the Ankang reservoir, China. The results demonstrate that release estimates show high skill, with normalized root-mean-square error (NRMSE) less than 0.12 and Kling-Gupta Efficiency (KGE) over 0.65. The performance of release estimates is varying with and influenced by inflow simulations and RWSC estimates, with NRMSE ranging from 0.09-0.12 and KGE from 0.65-0.74. Based on time-varying Bayesian Model Averaging (BMA) approaches and synthetic aperture radar (SAR) satellite datasets, more accurate inflow and RWSC estimates can be obtained, thus facilitating substantially release estimates. With multi-source satellite datasets, temporal scale of reservoir estimates is increased (monthly and bi-weekly), acting as a key supplement to in situ records. Overall, this study explores the possibility to reconstruct and facilitate reservoir release estimates in poorly gauged dammed basins using hydrological modeling techniques and multi-source satellite datasets.
\end{abstract}

Keywords: reservoir release; satellite altimetry; satellite imagery; SAR; hydrological models; BMA

\section{Introduction}

Reservoirs are essential tools in water resources management by providing immense societal and economic benefits in forms of hydroelectricity generation, flood control and water resources diversion [1,2]. The boom of reservoir impoundment has been underway since last century and will continue for the following decades, driven by climate change adaptation and population growth [3,4]. However, dam construction and regulation are disastrous for ecosystems and their negative impacts are well documented [5,6]. Great concerns have been raised about these impacts, particularly in transboundary river basins $[7,8]$. Therefore, reservoir monitoring is crucial for the well-being of regions with massive riparian population.

Reservoir release is an essential variable as it affects hydrological processes and water availability downstream $[9,10]$. Estimation of reservoir release is of great significance for 
downstream hindered by upstream reservoir behaviors. Traditionally, release estimation relied on in situ gauging stations or reservoir operational rules. However, in many countries, it is difficult for the public to obtain in situ data due to data access constraints [11,12]. Such field surveys are practically infeasible for global-scale applications, and encounter problems in specific basins with cascaded reservoirs [13]. Therefore, it is crucial to explore an alternative method for release estimation. Currently, a practical method is the combination of hydrological modeling techniques and satellite datasets.

Progress in remote sensing techniques enables the monitoring of reservoirs from space and helps characterizing reservoir dynamics across the globe $[14,15]$. Spaceborne sensors have been increasingly used to deliver valuable reservoir records such as water surface elevation (WSE) and surface water extent (SWE) [16-18]. WSE can be derived from satellite radar or laser altimeters (e.g., Jason-1/2/3, Sentinel-3, CryoSat-2, and ICESat-1/2) [19-21], while SWE can be estimated based on optical or SAR (synthetic aperture radar) imagery from e.g., MODIS (moderate resolution imaging spectroradiometer), Landsat MSS/TM/OLI, and Sentinel-1/-2 [22,23]. Through the Copernicus Sentinel mission, optical and SAR data in high resolution $(10-20 \mathrm{~m}$ ) has recently become free of charge and globally available with short latency of a few days or less, thus opening a new era for systematic mapping, assessment and monitoring of reservoirs [24]. Global maps on long-term surface water dynamics derived from optical satellite observations are readily accessible, e.g., the Global Surface Water Explorer from the European Commission Joint Research Center [25] and the Global Surface Water Dynamics from the University of Maryland [26].

Given the great potential of WSE and SWE for monitoring reservoir dynamics, research interest has been raised about reservoir water storage change (RWSC) estimates from space $[27,28]$. Currently, no spaceborne sensors can simultaneously estimate WSE and SWE for inland water bodies, except for the upcoming SWOT (Surface Water and Ocean Topography) mission. Therefore, two types of methods are commonly used to estimate RWSC [29]: (1) using overlapped observations of WSE and SWE from various spaceborne sensors and (2) constructing reservoir hypsometry (i.e., area-elevation curve), which then allows for the derivation of RWSC by one type of satellite observation (e.g., WSE). The limited uptake of the first method can be attributed to the fact that there have been very limited overlapping datasets due to different visiting times and orbits [30]. To overcome this limitation, other methods construct the hypsometry over reservoirs by using Digital Elevation Model [31], or using WSE and SWE to fit the hypsometry [32], or even neglecting changes of reservoir extent [33].

With inspiring work of RWSC estimation from space, recent studies focused on release estimation by coupling RWSC estimation with a reservoir model or hydrological models [34,35]. Muala et al. [36] forced a reservoir model with in situ inflow and satellite RWSC estimation to derive release at a 10-day time step. Bonnema and Hossain [37] used a pre-calibrated hydrological model to simulate inflow, and then derived monthly reservoir release in combination with satellite RWSC estimation. Their work focused on two parameters, water residence time and flow alteration rather than the accuracy of release estimation. More recently, Han et al. [33] simulated daily reservoir release using modeled inflow and operational rule. The operational rule is characterized by a storage curve, which is linearly interpolated by monthly reservoir storage estimation.

In the context of scarcity of in situ data, it is a pragmatic method to construct reservoir release by using satellite-based estimation of RWSC and inflow simulated by a precalibrated hydrological model. For example, Eldardiry and Hossain [34] established a modeling framework in the transboundary Nile River basin in Egypt to predict current and future streamflow. Despite the progress of previous studies, some limitations can be identified. Few of them address the uncertainty of individual estimates (both inflow and RWSC) and substantial release estimates [38,39]. Most studies simulate reservoir inflow with a single hydrological model [29,37], while calculating RWSC using one approach and failing to exploit the contributions of satellite datasets (WSE and SWE) on RWSC [33]. 
In light of the above, this study aims to reconstruct reservoir release by combining multi-source satellite datasets and hydrological modeling techniques, focusing on the impacts of satellite dataset and inflow uncertainty on release simulations. To address such concerns, ten inflow simulations based on hydrological models and blending schemes are used in combination with three RWSC estimates based on two satellite-based approaches. The experiments are carried out at Ankang reservoir, located in the Han River of Central China. It is noteworthy that our case study is not only to improve the accuracies of individual estimations (i.e., inflow and RWSC), but more importantly to understand the impacts of propagation of associated uncertainties on reservoir release. The following two research questions are to be addressed:

(1) What is the impact of different hydrological modeling and satellite-based approaches on the simulation of inflow and RWSC combined with multi-source satellite datasets?

(2) How do inflow simulations and RWSC estimates affect the accuracy of release estimates?

\section{Materials}

\subsection{Study Area}

The Ankang reservoir is located on the upstream of the Han River in China (Figure 1). The basin is dominated by a subtropical monsoon climate with a majority of rainfall from June to October. The upstream has a drainage area of $38,640 \mathrm{~km}^{2}$ with mean annual inflow of $568.78 \mathrm{~m}^{3} / \mathrm{s}$ [40]. We selected reservoir as a case study considering two aspects. First, concerning the availability of both in situ and satellite datasets, such a medium reservoir $\left(2.58 \mathrm{~km}^{3}\right.$ in water capacity and $70 \mathrm{~km}^{2}$ in water extent at the normal water level; see details in Table 1) [41] is suitable to investigate the effectiveness of our satellite-based approach, which has potential of being transferred to estimate release in ungauged basins with the same or larger reservoirs. Second, from a regional perspective, the release directly contributes to the inflow of Danjiangkou reservoir, thus, the case study can serve a basis for water resources management and provide a cooperative environment for all stakeholders of the Han River basin, which serves as the major water source of the South-to-North Water Diversion [42].

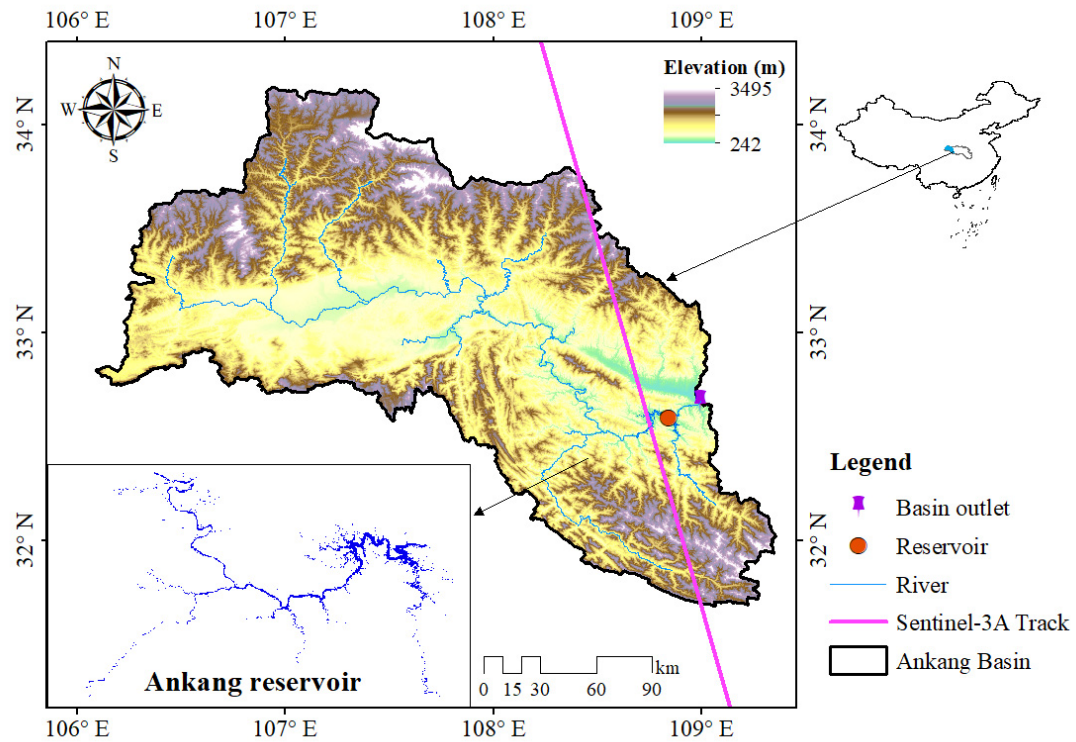

Figure 1. Location of the case study: Ankang Reservoir and its corresponding sub-basin over the Han River basin in Central China. 
Table 1. Characteristics of the Ankang reservoir.

\begin{tabular}{cccc}
\hline ID & Name & Units & Description \\
\hline 1 & Main function & - & $\begin{array}{c}\text { Flood control and hydropower generation } \\
\text { 38 (the ratio of water capacity to mean } \\
\text { annual inflow) }\end{array}$ \\
2 & Regulatory index & - & 1996 -present \\
3 & Operational period & Year & 850 \\
4 & Installed capacity & $\mathrm{MW}$ & 330 \\
5 & Normal water level & $\mathrm{m}$ & 305 \\
6 & Inactive water level & $\mathrm{m}$ & 325 \\
7 & Critical water level & $\mathrm{m}$ & 70 (at normal water level) \\
8 & Reservoir extent area & $\mathrm{km}^{2}$ & 2.58 (at normal water level) \\
9 & Water capacity & $\mathrm{km}^{3}$ &
\end{tabular}

\subsection{Satellite Radar Altimetry}

The Ankang satellite altimetry-derived water surface elevations are retrieved from Sentinel-3A. Sentinel-3A is one of the constellations of Sentinel-3 mission with a 27-day cycle. It has been operational since 2016 and thus, nearly five years of data are used in this study. Level 2 data are retrieved using the ESA GPOD (Grid Processing On Demand) platform (https: / /gpod.eo.esa.int/, last accessed on 8 February 2022). The level 2 product contains $20 \mathrm{~Hz}$ measurements including the range, satellite altitude, geoid height, waveforms and corrections. The range is retracked with SAMOSA+ retracker [43].

The water surface elevations WSE, are constructed via the following equations:

$$
W S E=H_{\text {alt }}-R_{\text {range }}-N_{\text {geo }}
$$

where $H_{\text {alt }}$ is the satellite altitude, $N_{\text {geo }}$ is the geoid height (i.e., the EGM2008 geoid model), $R_{\text {range }}$ is the distance from satellite to water surface, which can be expressed as:

$$
R_{\text {range }}=R_{\text {trac }}+R_{\text {retrac }}+R_{\text {atm }}+R_{\text {geo }}
$$

where $R_{\text {trac }}$ is the onboard tracker range that is the distance to the nominal bin in the waveform and $R_{\text {retrac }}$ is the re-tracking correction. $R_{a t m}$ is the atmospheric corrections including the ionospheric correction and the wet and dry tropospheric corrections. $R_{\text {geo }}$ is the geophysical corrections including pole tide, solid earth tide, and ocean loading tide.

Altimetry measurements over reservoir are firstly extracted based on the global surface water occurrence data set (https: / / global-surface-water.appspot.com/, last accessed on 8 February 2022). To ensure that a higher number of potential measurements are preselected, a low threshold of $10 \%$ occurrence is used. Secondly, a filtering process is performed for each pass to remove outliers using the median of absolute deviation [44]. Thirdly, the remaining measurements are used to construct WSE time series using "tyHydro" [45].

\subsection{Synthetic Aperture Radar Imagery}

The Ankang SAR images from Sentinel-1 mission are used to map SWE series over the case study considering two aspects. First, global products (e.g., Global Surface Water Dynamics and Global Surface Water Explorer) from optical satellite observations will tend to have a bias when used at the individual reservoirs. Monitoring SWE using optical data will underestimate water presence in cloudy regions, and is probably constrained by light availability in the darker months at higher latitudes. Second, the major advantage of SAR compared to optical and infrared imagery lies in its day/night observation capacity and its ability to penetrate clouds, hence providing a source for consistent monitoring irrespective of weather. Therefore, we applied a 4-year time series of Sentinel-1 images (early 2016 to 2020 May) to map the SWE dynamics over the reservoir.

Sentinel-1 is composed of a constellation of two near-polar satellites. Both satellites carry a C-band SAR instrument which collects data in all-weather conditions enabling continuous 12 day repeat monitoring. The workflow was adapted from Druce et al. [46] and 
consists of pre-processing, classification, and post-processing steps. In the pre-processing step, precise orbit vectors and range-Doppler terrain correction are applied to obtain a georeferenced SAR image. To exploit the difference in backscatter from water and non-water surfaces, a trained logistic regression model, trained using data from Global Surface Water Explorer, was used to convert backscatter values into water probability scores. Pixels with a probability score greater than $50 \%$ were subsequently classified as water and followed by a simple sieve filtering technique to reduce some inherent speckle noise. Finally, to mask out topography-induced radar shadows falsely classified as water, SRTM DEM was used to prepare a topographic mask that constrained the water detection to be within the high contour line $(+10 \mathrm{~m})$ of maximum reservoir extent.

\subsection{Model Input Forcings and Other Validated Datasets}

To facilitate modeling simulations and minimize uncertainties of input forcings, highquality satellite datasets are used to serve the meteorological inputs of hydrological models, i.e., precipitation and temperature. The GPM-Final precipitation products are used for their high quality (https: / / pmm.nasa.gov/GPM, last accessed on 8 February 2022). ERA5-Land temperature data at hourly and $0.1^{\circ} \times 0.1^{\circ}$ resolution are acquired from the Copernicus Climate Data Store (https:/ / cds.climate.copernicus.eu/, last accessed on 8 February 2022). Daily water level, storage change, inflow, and release are from the local watershed agency and National Hydrological Information Centre (http:/ / xxfb.mwr.cn/index.html, last accessed 8 February 2022) (Figure 2). Benchmark curve of elevation-storage is established using in situ measurements.
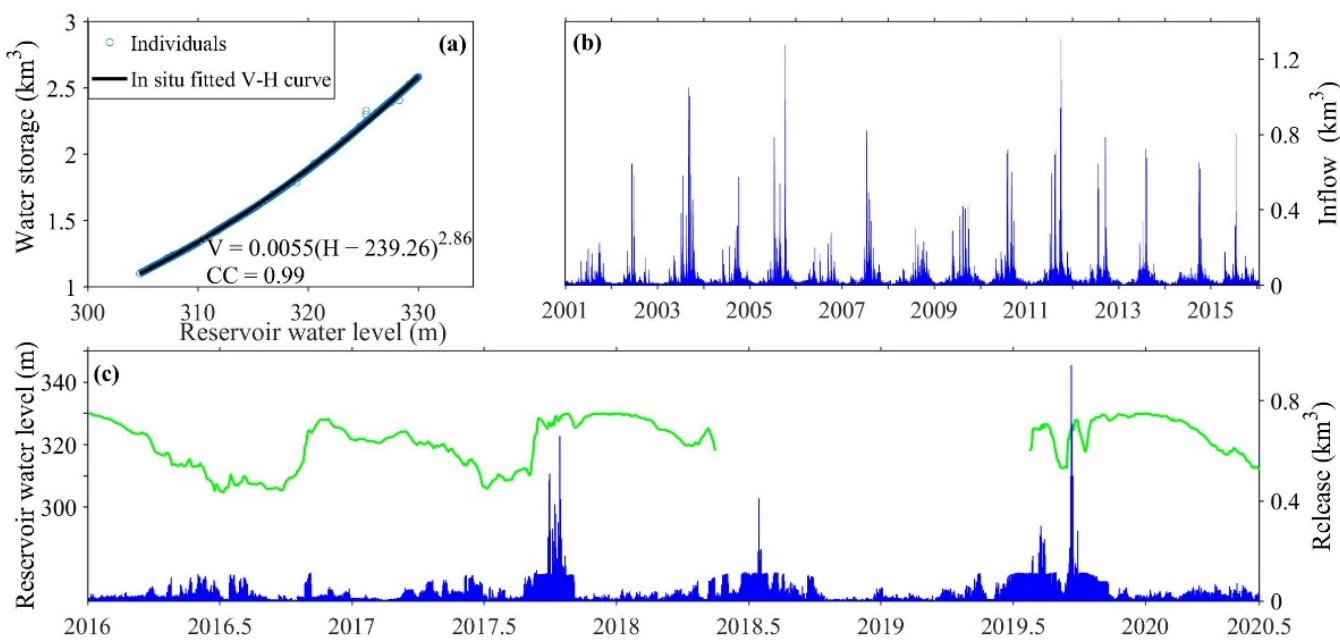

Figure 2. In situ records. (a) Elevation-storage curve. (b) Daily inflow spanning 2001-2015. (c) Daily release and water level (discontinuous in situ records) from 1 January 2016 to 31 May 2020.

\section{Methodology}

The flowchart of the entire workflow consists of three major steps and is shown in Figure 3. First, reservoir inflow forecasts using four hydrological models and six blending schemes. Second, RWSC estimates by two satellite-based approaches with processed satellite datasets. Third, calculation of release from a reservoir model and evaluation of the contributions and uncertainties of our satellite-based method in estimating reservoir release.

\subsection{Hydrological Modeling Techniques}

The four hydrological models (i.e., GR4J, IHACRES, SIMHYD and XAJ) are used to represent the uncertainty of inflow simulations. They are chosen considering three aspects. First, all of these models have been successfully applied in a plethora of catchments for a broad set of use cases such as streamflow simulation and parameter regionalization [47,48]. Second, considering complexities of structures and parameterizations (e.g., 4-15 parameters), 
these models are suitable for blending schemes to facilitate hydrological simulations. Third, as hydrological models are widely used, it is crucial to compare the contributions of different hydrological models to reservoir release estimates using our satellite-based approach.

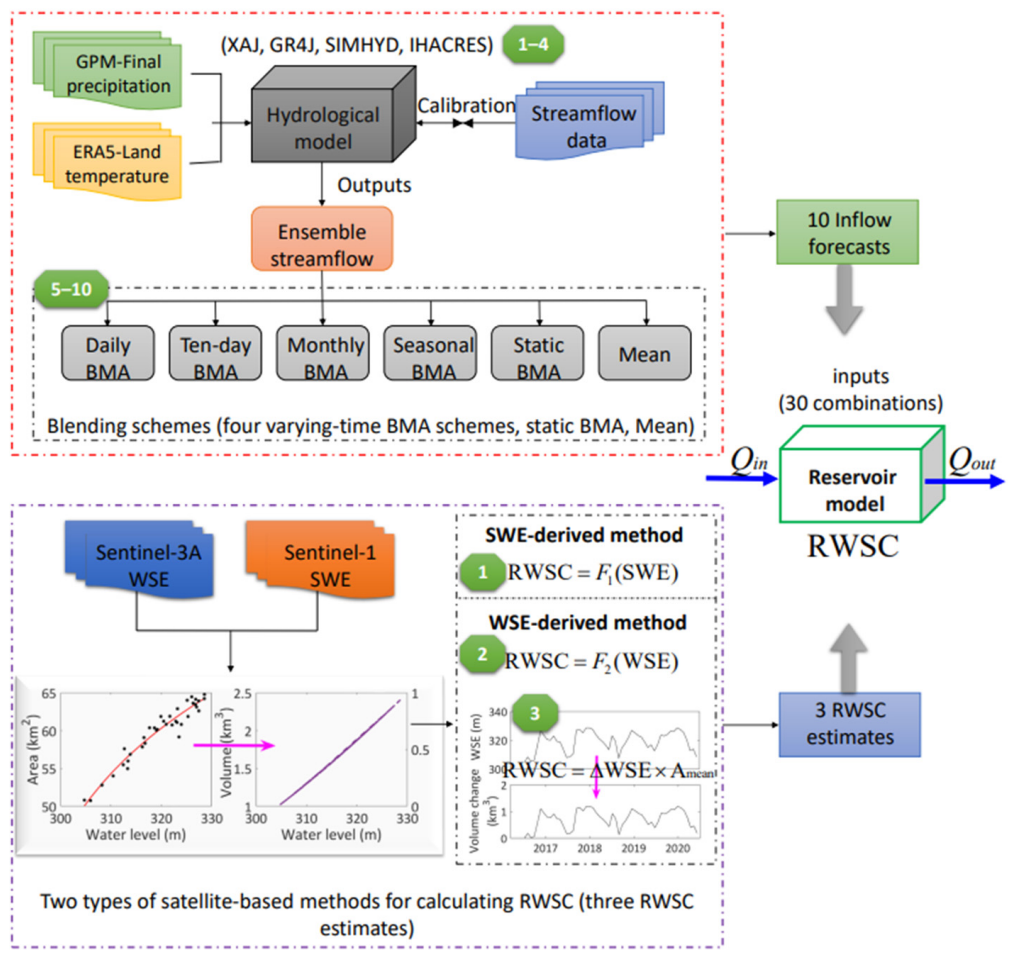

Figure 3. Flowchart of the methodology used to assess the contributions of multi-source satellite datasets and hydrological modeling techniques in estimating reservoir release.

The GR4J (Génie Rural à 4 paramètres Journalier) model was proposed by Perrin et al. [49]. It is one of the most widely-used hydrological models for its simplicity and good performance. Based on the unit hydrograph, two runoff components are routed to the outlet, contributing to the hydrograph. The IHACRES model has eight parameters and includes two major modules [50]. Effective rainfall is firstly calculated by a non-linear function. Then, the total runoff is partitioned into fast and slow flows. The SIMHYD (Simple Lumped Conceptual Daily Rainfall-Runoff) model is a simple model of the HYDROLOGY model [51] with nine parameters. Three storages (interception loss, soil moisture, and groundwater and routing process) are included and different runoff generation mechanisms are incorporated in this model. The XAJ (Xinanjiang) model was developed by Zhao [52], containing four major modules (evapotranspiration, runoff generation, separation, and routing) with 15 parameters.

The Bayesian Model Averaging (BMA) is employed to blend an ensemble of streamflow forecasts by different hydrological models, producing a new forecast posterior probability density function (PDF). Based on the law of total probability, given the observations $Y$ and the streamflow predictions of $S$ models $\left[f_{1}, f_{2}, \ldots, f_{S}\right]$, the posterior PDF of a forecast in BMA can be expressed as:

$$
p\left(y \mid f_{1}, f_{2}, \ldots, f_{s}, Y\right)=\sum_{s=1}^{S} p\left(f_{s} \mid Y\right) \cdot p\left(y \mid f_{s}, Y\right)
$$

where $p\left(y \mid f_{s}, Y\right)$ is the posterior distribution of $y$ given the model prediction $f_{s}$ and observations $Y . p\left(f_{s} \mid Y\right)$ represents the likelihood of ensemble predictions being correct, which reflects the performance of model $s$ in capturing observations $Y$. More simply, $p\left(f_{s} \mid Y\right)$ 
can be rewritten as $w_{s}$, the weight of each model, therefore, the general BMA approach in Equation (3) returns the weight averaged predicts of each model and can be rewritten as

$$
p\left(y \mid f_{1}, f_{2}, \ldots, f_{s}, Y\right)=\sum_{s=1}^{S} w_{s} \cdot p\left(y \mid f_{s}, Y\right)
$$

Therefore, the posterior PDF is the weighted average of model predictions using a static value of $w$ for each model. However, the general BMA may not always improve the accuracy of posterior PDF because ensemble predictions are time variant. In this work, time-varying (dynamic) $w$ values are used to facilitate streamflow simulations considering the seasonality or annual effects (Figure 3). To make it clearer, taking the monthly scales (12 $w$ values for each model) as example, the general BMA is repeated for each month, taking the ensemble simulations of each month as inputs, and then obtaining the $w$ of each model in the corresponding month. Finally, the entire series of posterior PDF are constructed with the dynamic $w$ values and ensemble simulations. The parameters $w$ are often iteratively optimized using the Expectation-Maximization (EM) algorithm by maximizing the log likelihood function [53]. EM is an efficient algorithm to iteratively optimize BMA parameters and contains three major modules. Firstly, the Box-Cox transformation is used to follow the Gaussian assumption of the conditional probability distribution $p\left(y \mid f_{s}, Y\right)$. Secondly, the objective function is set up, i.e., the $\log$ likelihood function $I(\theta)$, which is preferred and expressed as follows:

$$
I(\theta)=\log \left[\sum_{s=1}^{S} w_{s} \cdot g\left(y \mid f_{s}, \sigma_{s}^{2}\right)\right], \theta=\left\{w_{s}, \sigma_{s}^{2}, s=1,2, \ldots, S\right\}
$$

where $g(\cdot)$ denotes Gaussian distribution, $\theta$ is parameters (i.e., weights $w_{s}$ and variance $\sigma_{s}^{2}$ of each model) to be optimized. Thirdly, the EM algorithms were run for optimizing parameters.

The basin-averaged precipitation and potential evaporation are required as inputs to drive models. Potential evaporation is calculated based on the Oudin method, requiring temperature as inputs [54]. We split the meteorological forcings into three periods: 2001-2008 for calibration, 2009-2015 for validation, 1 January 2016 to 31 May 2020 for inflow forecast. Hydrological models are calibrated using the Shuffled Complex Evolution (SCE-UA) with the objective function of KGE [55]. Dynamic BMA at four varying-time scales (i.e., daily, ten-day, monthly, and seasonal) are developed and used to blend ensemble simulations, and two other blending approaches (static BMA, mean ensemble simulations) for comparison (Figure 3). The weights of BMA are fitted with the ensemble simulations of 2001-2015. To validate the performance of blending schemes, the leave-one-out approach is used [56], fitting BMA weights with the ensemble simulations for all years except 1 year for validation (15 combinations for calibration/validation). Then, we simulate the reservoir inflow from 1 January 2016 to 31 May 2020 for further release estimates.

\subsection{Satellite-Based RWSC Estimates}

The core of satellite-based estimation of RWSC is to construct hypsometry (i.e., elevation-area-storage curve). Based on the multi-source satellite datasets, we can fit the H-A curve with power or polynomial functions [57]. A power function with clear physical meanings is used to fit H-A curve in this study. To minimize the uncertainty, the data (WSE and SWE) acquired within 5 days interval are used to fit the curve by Least Squares Method. When H-A curve is determined, $\mathrm{H}-\mathrm{V}$ or $\mathrm{A}-\mathrm{V}$ curve is subsequently derived following the mathematic method.

$$
A=\frac{d V}{d h}=F_{1}{ }^{\prime}(h)=f_{1}(h)=a\left(h-h_{0}\right)^{b}
$$




$$
V=\left\{\begin{array}{l}
F_{1}(h)=\int_{h_{0}}^{h} f_{1}(h)=\frac{a}{b+1}\left(h-h_{0}\right)^{b+1} \\
F_{2}(A)=F_{2}\left(f_{1}^{-1}(A)\right)=\frac{a}{b+1}\left(\frac{A}{a}\right)^{\frac{b+1}{b}}
\end{array}\right.
$$

where $A\left[\mathrm{~L}^{2}\right], V\left[\mathrm{~L}^{3}\right]$ and $h$ (i.e., WSE) $[\mathrm{L}]$ are the reservoir area, storage, and elevation, respectively. $a$ [dimensionless], $b$ [dimensionless], and $h_{0}$ [L] are the parameters of elevationarea curve. Pre-defined parameter ranges are the same with Zhong et al. [2], which suggests that a narrower range is enough to cover a wide range of elevation-area curves. RWSC $\left[\mathrm{L}^{3}\right]$ can be determined by H-V curve and WSE or A-V curve and SWE data. Here, we refer to as WSE-derived method and SWE-derived method. In cases where no satellite imagery available, we extend the WSE-derived method by assuming constant and stageindependent reservoir surface area. Therefore, RWSC can be calculated by multiplying the difference of satellite altimetry observations with a mean area [58]. The three RWSC $(\mathrm{V}(\mathrm{h}), \mathrm{V}(\mathrm{A})$, and constant $\mathrm{A})$ estimates are then used as inputs of reservoir model for release estimates and further validation against in situ records (Figure 3).

\subsection{A Simple Reservoir Model}

Reservoir release can be obtained by using a reservoir model, Equation $(8)[29,57]$.

$$
O=I-R W S C
$$

where release $O\left[\mathrm{~L}^{3}\right]$ is the difference between reservoir inflow $I\left[\mathrm{~L}^{3}\right]$ and RWSC $\left[\mathrm{L}^{3}\right]$ at a certain time step (e.g., two adjacent satellite altimetry observations with a 27-day cycle). The seepage is assumed negligible. Although a small fraction of evaporation is lost, it can be compensated by precipitation over the reservoir (i.e., evaporation and precipitation account for $0.5 \%$ and $0.4 \%$ of mean monthly inflow, respectively). Particularly in the case study with subtropical monsoon climate, evaporation rate is small. Thus, it is reasonable to neglect these water fluxes for their little impacts on reservoir release [33,58].

\section{Results}

\subsection{Inflow Simulations}

The performances of four hydrological models are assessed by KGE, PBIAS, NSE, $\operatorname{logNSE}, \mathrm{CC}, \mathrm{BR}$, and RV (Figure 4 and Table 2). The values of KGE and PBIAS reveal that all hydrological models perform well with KGE $>0.6$ and absolute PBIAS $<0.15$. Nonetheless, there are some differences. For example, the GR4J exhibits the best simulation skills in terms of highest KGE, NSE, and CC values during calibration period, while the XAJ achieves the best scores during validation period. The XAJ exhibits best skills in reproducing low flows according to its highest $\operatorname{logNSE}$ values over 0.65 , while the IHACRES is optimal in RV with nearly one. None of these models can fully replicate the variations of streamflow. High flows are often underestimated while low flows tend to be overestimated. Large discrepancies can be found in the evaluation metrics and streamflow hydrographs, indicating that it is necessary to generate a more accurate forecast from the ensemble simulations considering their uncertainties.

Figure 5 shows the performance of blending approaches as well as the individuals (i.e., simulations of each hydrological model). The blending approaches perform better than the individuals in terms of evaluation metrics. For example, the KGE values of the blending approaches range from $0.77-0.85$, increased by $6.9-18.1 \%$ compared with those of the individuals. The uncertainties are greatly reduced by using the blending approaches according to the evaluation metrics values during validation period. It is informative to notice that dynamic BMA schemes achieve better scores than the other two blending approaches, except for dynamic BMA at seasonal scale. Dynamic BMA schemes outperform the other two approaches in terms of NSE, logNSE, CC, PBIAS, and RV metrics. However, static BMA is the best in terms of BR metrics, and also outperforms dynamic BMA at longer time scales such as monthly or seasonal scales, with KGE value improved by 0.2 . 
As shown in Figure 5, the best-performing model is dynamic BMA at daily scale. To consider the impacts of different times in dynamic BMA, the trends of three evaluation metrics (KGE, NSE, and logNSE) are analyzed (Figure 6). The results indicate that the performance of dynamic BMA improves as times increase. The optimal weights of dynamic BMA are shown in Figure 7, supporting the dynamics of probability of the ensembles being correct at different times. Overall, dynamic BMA can facilitate hydrological simulations through considering model uncertainties, and daily time scale is recommended when using dynamic BMA.

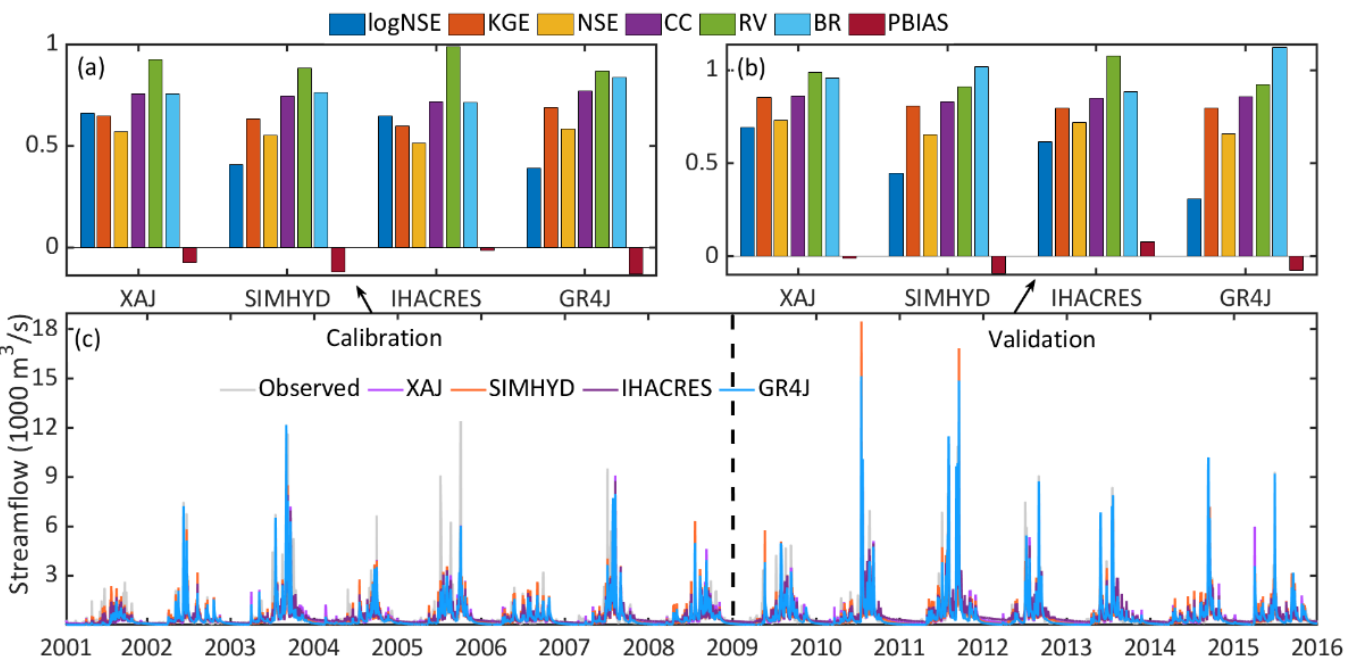

Figure 4. Comparison of observed and simulated reservoir inflow using four hydrological models. (a,b) Statistical values during calibration period (2001-2008) and validation period (2009-2015), respectively. (c) Hydrographs (2001-2015).

Table 2. Statistical metrics evaluating the performance of estimations of inflow, release, RWSC, and satellite observations.

\begin{tabular}{|c|c|c|c|}
\hline Metric & Abbreviation & Expression & Perfect Score \\
\hline Kling-Gupta Efficiency & KGE & $1-\sqrt{(\mathrm{CC}-1)^{2}+(\mathrm{BR}-1)^{2}+(\mathrm{RV}-1)^{2}}$ & 1 \\
\hline Correlation coefficient & $\mathrm{CC}$ & $\frac{\sum_{j=1}^{N}\left(S_{j}-\bar{S}\right)\left(G_{j}-\bar{G}\right)}{\sqrt{\sum_{j=1}^{N}\left(G_{j}-\bar{G}\right)^{2}} \sqrt{\sum_{j=1}^{N}\left(S_{j}-\bar{S}\right)^{2}}}$ & 1 \\
\hline Bias Ratio & $\mathrm{BR}$ & $\overline{\bar{G}}$ & 1 \\
\hline Relative Variability & RV & $\frac{\sqrt{\sum_{j=1}^{N}\left(S_{j}-\bar{S}\right)^{2}}}{\sqrt{\sum_{j=1}^{N}\left(G_{j}-\bar{G}\right)^{2}}}$ & 1 \\
\hline Nash-Sutcliffe Efficiency & NSE & $1-\sqrt{\frac{\sum_{j=1}^{N}\left(S_{j}-G_{j}\right)^{2}}{\sum_{j=1}^{N}\left(G_{j}-\bar{G}\right)^{2}}}$ & 1 \\
\hline $\begin{array}{c}\text { Logarithmic } \\
\text { Nash-Sutcliffe Efficiency }\end{array}$ & $\log N S E$ & $1-\sqrt{\frac{\sum_{j=1}^{N}\left(\log \left(S_{j}\right)-\log \left(G_{j}\right)\right)^{2}}{\sum_{j=1}^{N}\left(\log \left(G_{j}\right)-\log (\bar{G})\right)^{2}}}$ & 1 \\
\hline Percent bias & PBIAS & $\frac{\sum_{j=1}^{N}\left(S_{j}-G_{j}\right)}{\sum_{j=1}^{N} G_{j}} \times 100 \%$ & 0 \\
\hline Root-mean-square error & RMSE & $\sqrt{\frac{\sum_{j=1}^{N}\left(S_{j}-G_{j}\right)^{2}}{N}}$ & 0 \\
\hline $\begin{array}{c}\text { Normalized } \\
\text { root-mean-square error }\end{array}$ & NRMSE & $\frac{\mathrm{RMSE}}{\max \left(G_{j}\right)-\min \left(G_{j}\right)}$ & 0 \\
\hline
\end{tabular}

$G_{j}\left(S_{j}\right)$ indicates gauging observation (satellite/model estimates); $N$ represents total length; $\bar{G}(\bar{S})$ is the mean value of gauging observations (satellite/model estimates). 

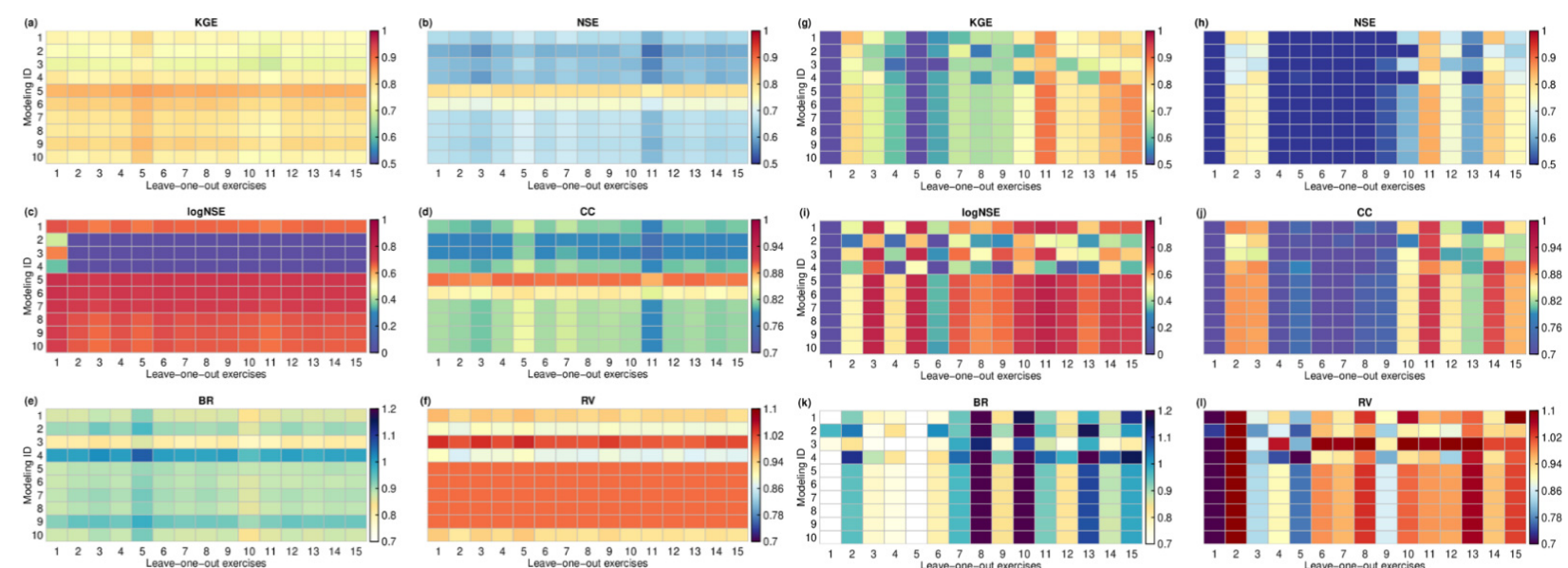

Figure 5. The statistical values of various hydrological modeling techniques during calibration $(\mathbf{a}-\mathbf{f})$ and validation ( $\mathbf{g}-\mathbf{l})$ periods. The modeling ID refers to ten hydrological modeling techniques (Figure 3).
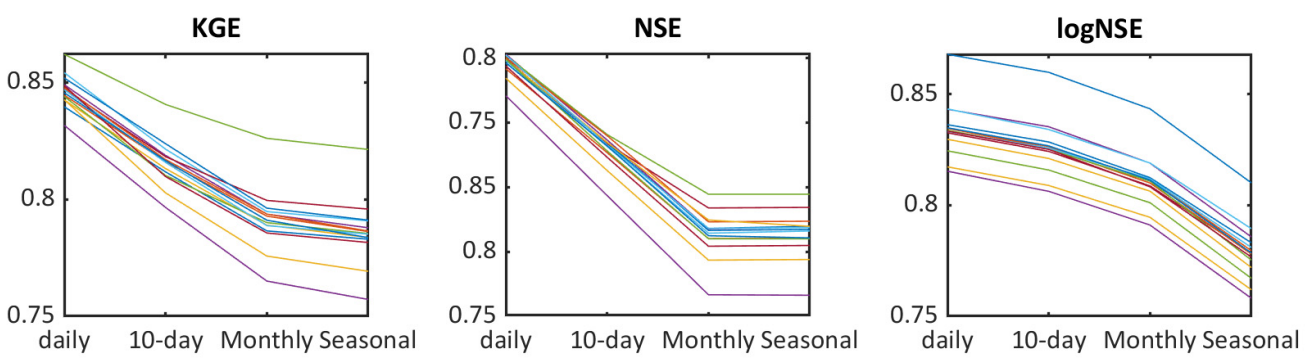

Figure 6. The trends of three evaluation metrics under the varying-time BMA schemes. Lines in the figure indicate the results of different exercises of leave-one-out approach.
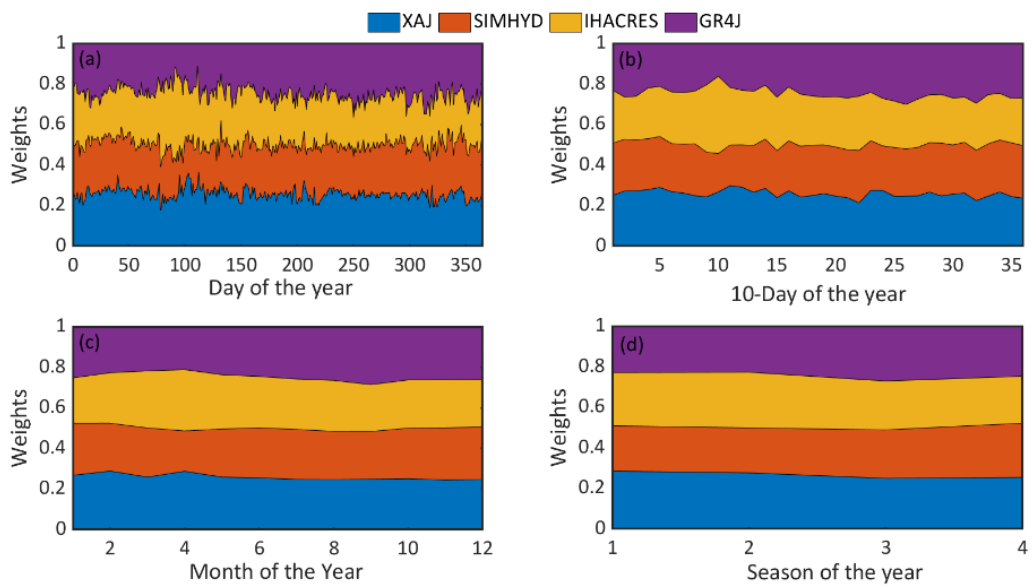

Figure 7. The temporal distribution of weights in the dynamic BMA schemes. (a) Daily scale, (b) 10-day scale, (c) Monthly scale, (d) Seasonal scale.

\subsection{RWSC Estimates}

The key factors concerning the performance of RWSC estimates are the accuracy of satellite WSE and SWE datasets, which are firstly evaluated against in situ records. The performance of altimetry measurements is evaluated by three statistical metrics (RMSE, BIAS and CC) and considered moderate based on statistical assessment, visual inspection and previous publications [59]. The values of RMSE (bias-removed), BIAS, and CC are $0.36 \mathrm{~m},-1.32 \mathrm{~m}$, and nearly one, respectively (Table 3). It should be noted that the bias is 
likely not a measurement bias but a geoid issue. Datum conversion is not publicly available; thus, we compared the WSE anomalies by removing their mean values. Seasonal deviations are also examined and it was found that high water levels are more accurate in terms of a lower RMSE value of $0.16 \mathrm{~m}$, while low water levels are less accurate with a higher RMSE value of $0.34 \mathrm{~m}$. To validate the performance of SWE datasets, we plotted the time series of in situ water level records and satellite SWE at the overlapping dates. The time series show good agreements, with CC exceeding 0.97. Overall, clear patterns can be found in WSE and SWE, illustrating reservoir behaviors of seasonal filling and emptying (Figure 8).

Table 3. Accuracies of satellite WSE and SWE datasets as well as RWSC estimates.

\begin{tabular}{ccccc}
\hline ID & RMSE & NRMSE & BIAS & CC \\
\hline WSE & $0.36(\mathrm{~m})$ & - & $-1.32(\mathrm{~m})$ & 1 \\
SWE & - & - & - & 0.97 \\
RWSC $_{1}$ & $0.099\left(\mathrm{~km}^{3}\right)$ & 0.064 & $-0.003\left(\mathrm{~km}^{3}\right)$ & 0.91 \\
RWSC $_{2}$ & 0.026 & 0.019 & 0.004 & 1 \\
RWSC $_{3}$ & 0.030 & 0.023 & 0.006 & 1 \\
\hline
\end{tabular}

RWSC $_{\mathrm{i}}$ indicates the $i^{\text {th }}$ satellite-based RWSC estimates (see details in Figure 3).
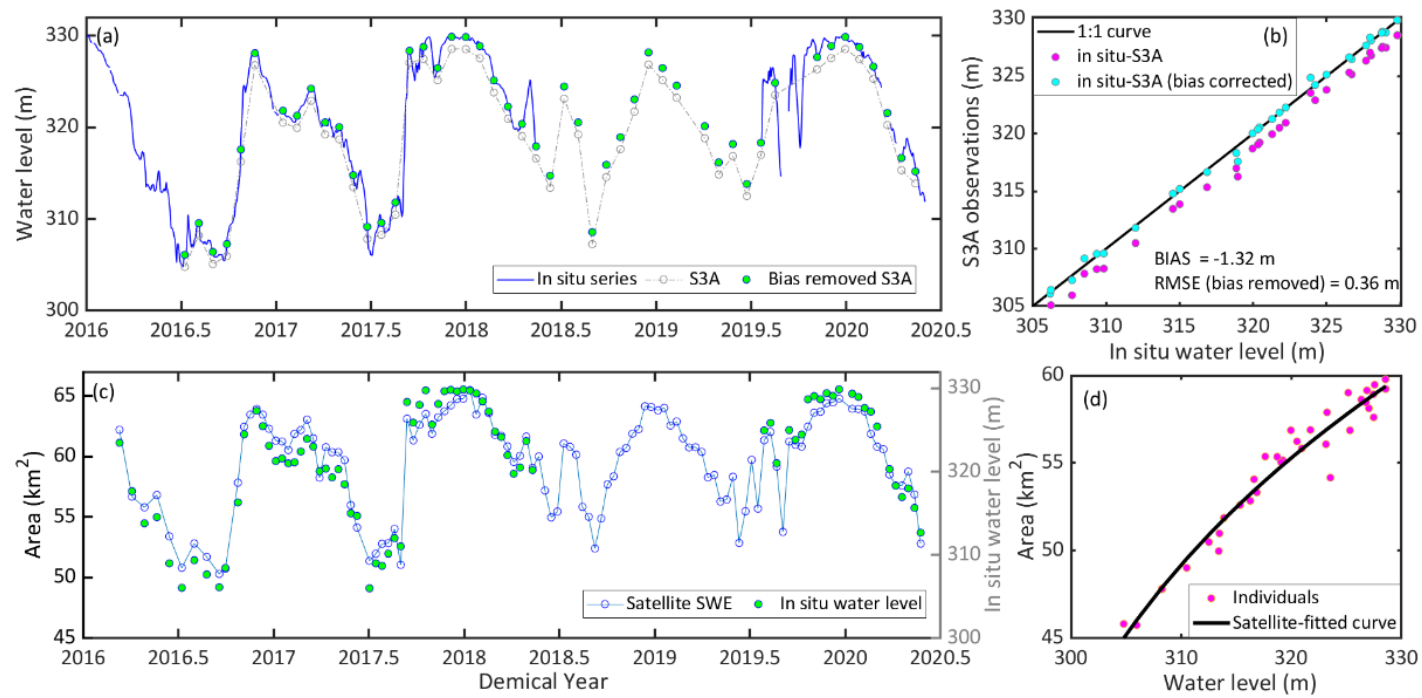

Figure 8. The relationships between satellite datasets and in situ records. (a,b) Temporal series and scatter plots of Sentinel-3A and in situ WSE. (c) Temporal series of satellite SWE and in situ WSE. (d) The H-A curve fitted by satellite SWE and WSE datasets.

Figure 9 shows the error series of RWSC. The performance of RWSC is assessed by four metrics (RMSE, NRMSE, BIAS, and CC) and considered good based on visual inspection and statistical assessment (Table 3). WSE-derived method performs better than SWEderived method in RWSC. For example, the values of RMSE, NRMSE, BIAS, and CC for WSE-derived and SWE-derived RWSC are $0.026 / 0.099 \mathrm{~km}^{3}, 0.019 / 0.064,0.004 /-0.003 \mathrm{~km}^{3}$, and $0.996 / 0.914$, respectively. Two types of WSE-derived methods perform very similarly, indicating that main source of RWSC error comes from SWE and a combination of SWE and WSE. To figure out the impacts of the propagation of associated satellite datasets uncertainties on RWSC, the error series of WSE, water level change, RWSC estimates as well as elevation-storage curves are depicted in Figure 9. There are three important error sources in the simulated RWSC: elevation error, surface extent error, and error from their combinations. The combinations represent the propagation processes from satellite datasets uncertainties to RWSC (satellite-fitted elevation-storage curve). We established the area-elevation relationship and then derived elevation-storage curve using satellite SWE and WSE (Figure 9d,e). Apparent shifts are found in the satellite-fitted elevation-storage 
curve (Figure 9d). To eliminate systematic bias, both in situ and satellite-fitted curves are transformed to storage anomaly. We found that the slope of satellite-fitted curve is smaller than that of in situ curve at high water levels, and larger at low water levels (Figure 9e). There is room for improvement and increasing the accuracy of the elevation-storage curve using satellite datasets. Nevertheless, the close agreement between satellite-fitted and in situ curves established a good level of trustworthiness in our satellite-based approaches of calculating RWSC. Based on such satellite-fitted curves, we could obtain RWSC estimates using either SWE or WSE time series. Satellite SWE errors are the main error source of RWSC, supporting the work of Bonnema and Hossain [58]. It is worth noting that there is small difference between two types of SWE-derived RWSC estimates, thereby demonstrating the potential of estimating RWSC with satellite WSE datasets and constant area. The advantage of current satellite sensors cannot be overlooked. Although satellite altimetry measurements are carefully processed, large errors occur sometimes, e.g., at 43rd observations, contributing to the large error of RWSC (Figure 9b). When assuming the reservoir extent is constant, RWSC is calculated by using elevation change, thus, large error of RWSC occurs when two adjacent altimetry measurements are separately underestimated and overestimated. Taking the 15th observations as example, we examined the seasonal performance of satellite altimetry measurements and found there is no obvious pattern in elevation error during the transiting periods. As a result, it is better to reduce the satellite datasets errors before calculating RWSC, which also suggests that WSE-derived method is more suitable to estimate reservoir storage dynamics.
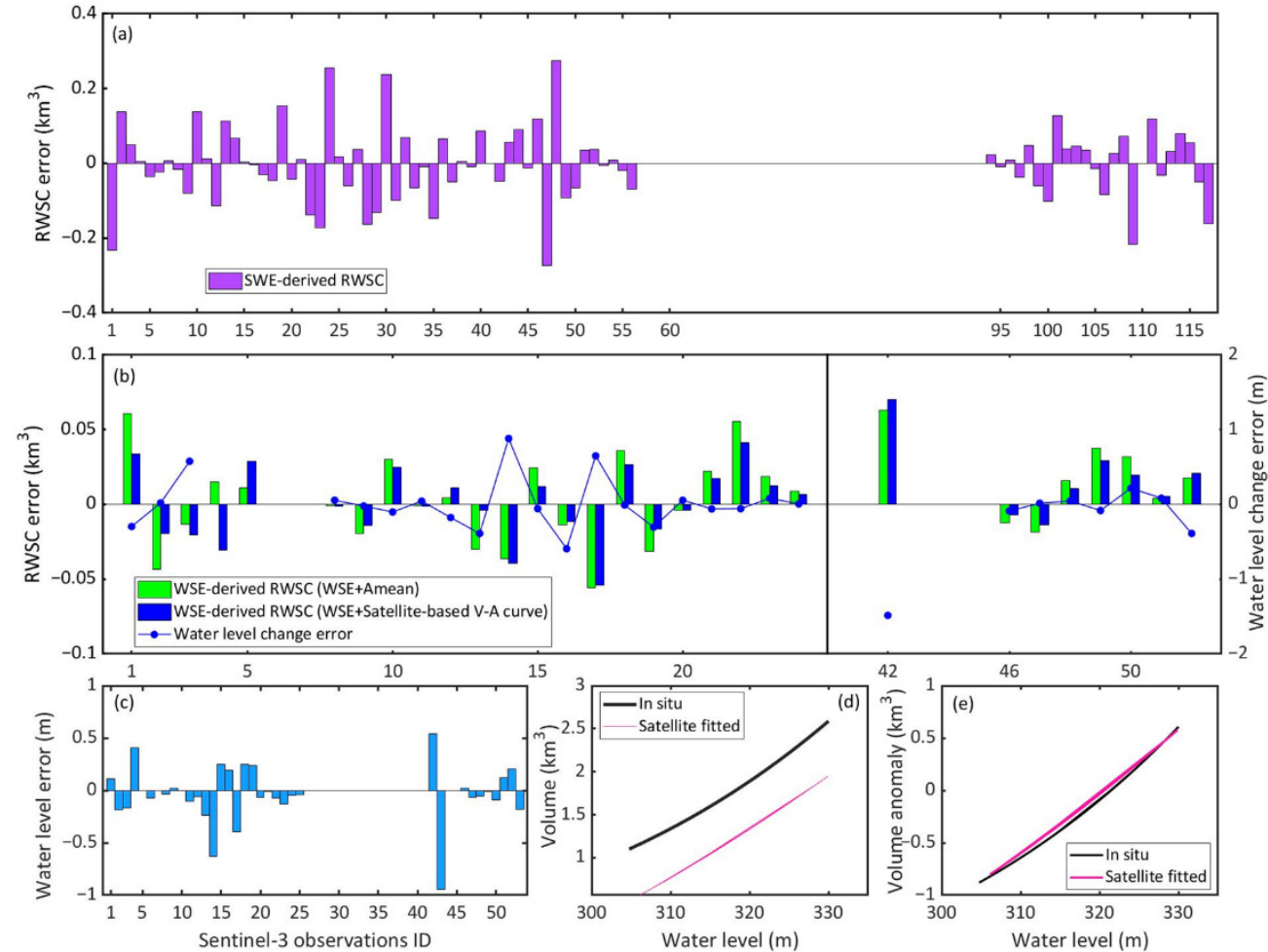

Figure 9. Error series and relationships of reservoir elevation-storage. Error series of (a) SWEderived RWSC, (b) WSE-derived RWSC and water level change, (c) WSE. (d,e) Relationships of elevation-storage. The numbers on the $x$-axis $(a, b, c)$ refer to the IDs of SWE, WSE, and WSE change observations, respectively.

\subsection{Reservoir Release Estimates}

The hydrographs of reservoir release with different input combinations are depicted in Figure 10, and the results of evaluation metrics are shown in Figure 11. Almost all estimated releases show similar patterns to the observations, with KGE and NSE values exceeding 0.65 and NRMSE values below $0.12 \mathrm{~km}^{3}$, favoring the success of satellite-based approach. Through 
improving the accuracy of individual estimates of inflow and RWSC, more accurate release estimates are obtained (Figure 11). Moreover, impacts of reservoir on natural streamflow are assessed in Figure 10, highlighting the value of satellite-based approach.
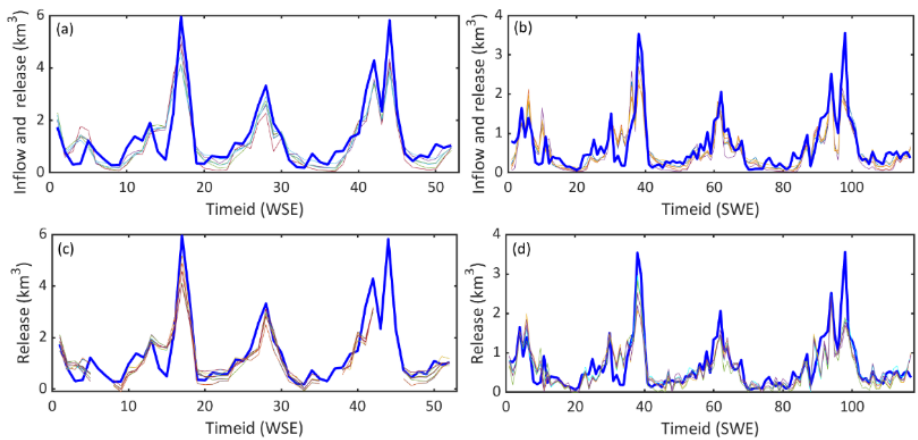

Figure 10. Reservoir flow series from 1 January 2016 to 31 May 2020. (a,b) Ten inflow forecasts and observed release at 27-day and 12-day resolution, respectively. (c,d) Reservoir release estimates by different input combinations at 27-day and 12-day resolution, respectively. The blue line indicates the in-situ reservoir release.
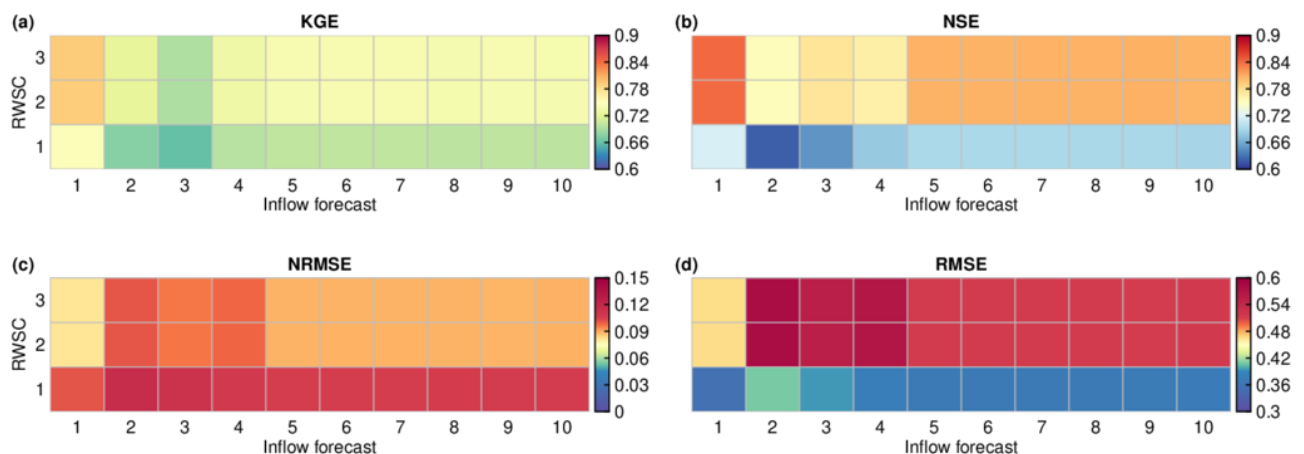

Figure 11. Performance statistics of estimated release by different input combinations. (a) KGE, (b) NSE, (c) NRMSE, (d) RMSE.

\section{Discussion}

The satellite datasets can characterize the dynamics of reservoirs in otherwise ungauged basins. We select the most recent products and explore how new satellites may deliver useful measurements over reservoirs. To our knowledge, this study firstly exploits the contributions of satellite datasets from Sentinel missions on RWSC and release estimates. SAR expands the applicability of satellite missions in monitoring any inland water body. This is the case for the Ankang, i.e., a reservoir with long-narrow shape and medium size in area and storage. Sentinel missions as Sentinel-1/-3 can deliver useful data and produce valuable information such as RWSC and release. Our SAR-based classification for mapping surface water areas performs considerably better than Landsat-based maps [46], and this will make the estimation of reservoir area more robust and hence improve the accuracy of RWSC and release estimates. The findings indicate that the accuracy of RWSC estimates is more sensitive to satellite SWE while less sensitive to WSE. These discrepancies can be attributed to the reservoir characteristic. To incorporate this property, we plan to evaluate the SWE maps as a next step and may lead to further improvements in the results. To improve satellite-based estimations of RWSC and release, some aspects can be considered. The first is to examine the variations of reservoirs in area [28]. For reservoirs with small variation in area, a simple method (i.e., V (constant A)) would be efficient; otherwise, a use of multi-source satellite datasets is recommended. The second aligns with advances in constructing reservoir geometry using digital elevation model. Liu et al. [9] modeled the 
reservoir bathymetry with SRTM DEM and satellite imagery. The principle is to utilize geomorphological similarity and topographical continuity of reservoirs to model bathymetry. Last but not least, by ensuring that satellite datasets are accurate with filtering algorithms, performances of RWSC and release estimates can be potentially greatly increased.

The inflow is a key factor influencing the performance of release estimates, which is reflected by different performances of release using various hydrological modeling techniques (Figures 10 and 11). Besides, the streamflow errors (e.g., timing errors) are likely eliminated when aggregating daily inflow at monthly scale, thus reducing the contributions of varying-time BMA to release estimates. It should be noted that release estimates at shorter scales are also dependent on the satellite-based estimation of RWSC, where we also contributed by deriving bi-weekly RWSC estimation using continuous surface extents. In the case study, reservoir experiences seasonal filling and emptying, which are fully captured by satellite datasets (Figure 8). This is illustrated by Figure A1, which shows monthly average reservoir surface elevation, demonstrating the variations of reservoir operating patterns as well as the potential of estimating release at shorter time scales based on this altimetry-based rule. Although such a satellite-based rule is less applicable, it could be a reliable reference of daily release estimates. For example, Han et al. [33] simulated daily release based on a reservoir rule, which is represented by a storage curve interpolated by monthly storage. The performance of RWSC and release estimates is also expected to be improved as the temporal resolution of satellite datasets is increasing (upcoming SWOT and multiple altimetry missions), potentially producing accurate release simulations at shorter time scales [60].

The results can be valid for the Han River basin and regions with similar climate conditions and water reservoirs in size. In spite of good performance of our approach, further studies should be done for a bigger picture of the performance of reservoir release estimates after repeating our works in other regions. First, the evaporation is negligible compared to inflow in the case study with humid climate conditions, while it could be a potential key variable in semiarid regions [61,62]. Second, the performance of satellite datasets varies with reservoirs of varying sizes and functions. Third, bias is associated with local climates and geographies, bringing a challenge for a wide generalization of the findings.

While the modeling framework adopted in-situ streamflow to calibrate hydrological models and the loss of accuracy is expected when this data is not available, the findings still foster further research initiatives in understanding impacts of reservoirs on river systems in ungauged basins. Progress in remote sensing technologies creates more opportunities in ungauged basins. Several studies have informed hydrological models (i.e., model parameter calibration) with multi-source satellite datasets such as river water level [63], soil moisture [64], evapotranspiration [65], and total water storage [66]. It is expected that more accurate inflow simulations can be still produced by our varying-time BMA schemes, bringing benefits for more accurate estimation of release. The uncertainties of satellite datasets should be paid more attention, and evaluation of the SWE maps accuracy would be desirable and may lead to further improvements in the results. Without additional observations, satellite-based estimations of reservoir records can be the best reference in ungauged basins.

\section{Conclusions}

This study evaluates the ability of reconstructing reservoir release for poorly gauged dammed basins using multi-source satellite datasets and hydrological modeling techniques. The experiment is performed at the Ankang reservoir of the Han River basin in China, using ten inflow simulations based on hydrological models and blending schemes and three RWSC estimates based on two satellite-based approaches. The main findings are as follows.

The satellite-based approach achieves satisfactory results in estimating reservoir states such as RWSC and release, thereby supporting further research on dammed basins. The 
performance of release estimates is variable and greatly affected by the accuracies of inflow and RWSC estimates. Through dynamically correcting the posterior probabilities at temporal scales, more accurate inflow simulations can be produced from our varying-time BMA schemes, bringing benefits for more accurate estimation of release. We contribute to the current understanding of satellite-based estimation of RWSC, which are calculated based on most recent SAR multi-source satellite WSE and SWE datasets. With multi-source approaches, both temporal scale and accuracy of reservoir estimates are increased (i.e., monthly and bi-weekly), acting as a key supplement to in situ records. The results indicate that the accuracy of RWSC estimates is more sensitive to satellite SWE while less sensitive to satellite WSE. In cases where no satellite imagery are available, we suggest calculating RWSC by multiplying elevation changes with constant area as an effective alternative source of information.

Accurate estimation of release is of great significance to hydrologists and local managements in the background of booming reservoir impoundments. The satellite-based estimations of reservoir states (e.g., release and RWSC) are expected to foster further research initiatives in understanding impacts of reservoirs on river systems. Given the background of booming satellite missions, this study can also broaden our understanding of the advantages and limitations when integrating satellite datasets into hydrological modeling for poorly gauged dammed basins.

Author Contributions: Conceptualization, Y.S. and D.L.; methodology, Y.S.; formal analysis, J.W.; data curation, X.Z., C.T., D.D. and K.N.; writing—original draft preparation, Y.S.; writing—review and editing, Y.S., L.J., P.B.-G. and D.L.; visualization, Y.S. and J.Y.; supervision, D.L.; project administration, D.L.; funding acquisition, D.L. All authors have read and agreed to the published version of the manuscript.

Funding: This research was funded by National Natural Science Foundation of China, grant number 51879194, 51579183 and 52009091 . This work is also partly funded by the Danida Fellowship Centre (File number: 18-M01-DTU). The numerical calculations in this paper have been done on the supercomputing system in the Supercomputing Center of Wuhan University.

Institutional Review Board Statement: Not applicable.

Informed Consent Statement: Not applicable.

Data Availability Statement: Not applicable.

Conflicts of Interest: The authors declare no conflict of interest.

\section{Appendix A}

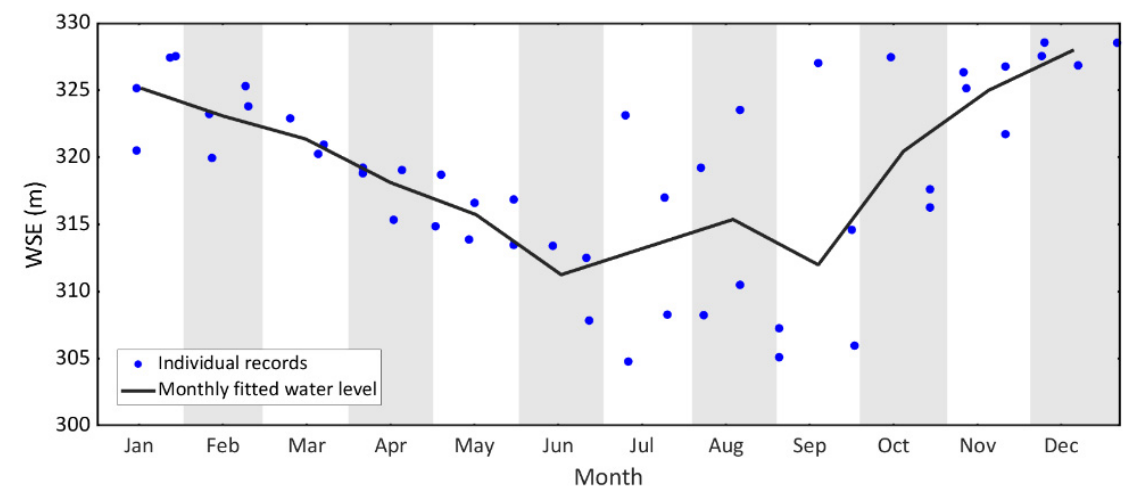

Figure A1. The satellite-based reservoir operating rules which can be represented as the monthly averaged reservoir WSE from satellite altimetry. 


\section{References}

1. Intralawan, A.; Wood, D.; Frankel, R.; Costanza, R.; Kubiszewski, I. Tradeoff analysis between electricity generation and ecosystem services in the lower Mekong Basin. Ecosyst. Serv. 2018, 30, 27-35. [CrossRef]

2. Zhong, R.; Zhao, T.; Chen, X. Hydrological model calibration for dammed basins using satellite altimetry information. Water Resour. Res. 2020, 56, e2020WR027442. [CrossRef]

3. Gutenson, J.L.; Tavakoly, A.A.; Wahl, M.D.; Follum, M.L. Comparison of generalized non-data-driven lake and reservoir routing models for global-scale hydrologic forecasting of reservoir outflow at diurnal time steps. Hydrol. Earth Syst. Sci. 2020, 24, 2711-2729. [CrossRef]

4. Lehner, B.; Liermann, C.R.; Revenga, C.; Vörösmarty, C.; Fekete, B.; Crouzet, P.; Döll, P.; Endejan, M.; Frenken, K.; Magome, J.; et al. High-resolution mapping of the world's reservoirs and dams for sustainable river-flow management. Front. Ecol. Environ. 2011, 9, 494-502. [CrossRef]

5. Cooper, A.R.; Infante, D.M.; Daniel, W.M.; Wehrly, K.E.; Wang, L.; Brenden, T.O. Assessment of dam effects on streams and fish assemblages of the conterminous USA. Sci. Total Environ. 2017, 586, 879-889. [CrossRef] [PubMed]

6. Li, R.; Xiong, L.; Xiong, B.; Li, Y.; Xu, Q.; Cheng, L.; Xu, C.-Y. Investigating the downstream sediment load change by an index coupling effective rainfall information with reservoir sediment trapping capacity. J. Hydrol. 2020, 590, 125200. [CrossRef]

7. Stone, R. Dam-building threatens Mekong fisheries. Science 2016, 354, 1084-1085. [CrossRef] [PubMed]

8. Zarfl, C.; Lumsdon, A.E.; Berlekamp, J.; Tydecks, L.; Tockner, K. A global boom in hydropower dam construction. Aquat. Sci. 2014, 77, 161-170. [CrossRef]

9. $\quad$ Liu, K.; Song, C.; Wang, J.; Ke, L.; Zhu, Y.; Zhu, J.; Ma, R.; Luo, Z. Remote sensing-based modeling of the bathymetry and water storage for channel-type reservoirs worldwide. Water Resour. Res. 2020, 56, e2020WR027147. [CrossRef]

10. Tiwari, A.D.; Mishra, V. Prediction of reservoir storage anomalies in India. J. Geophy. Res. Atmos. 2019, 124, 3822-3838. [CrossRef]

11. Mulligan, M.; van Soesbergen, A.; Sáenz, L. GOODD, a global dataset of more than 38,000 georeferenced dams. Sci. Data 2020, 7, 31. [CrossRef] [PubMed]

12. Plengsaeng, B.; Wehn, U.; van der Zaag, P. Data-sharing bottlenecks in transboundary integrated water resources management: A case study of the Mekong River Commission's procedures for data sharing in the Thai context. Water Int. 2014, 39, 933-951. [CrossRef]

13. Ashoori, N.; Dzombak, D.A.; Small, M.J. Identifying water price and population criteria for meeting future urban water demand targets. J. Hydrol. 2017, 555, 547-556. [CrossRef]

14. Duan, Z.; Bastiaanssen, W.G.M. Estimating water volume variations in lakes and reservoirs from four operational satellite altimetry databases and satellite imagery data. Remote Sens. Environ. 2013, 134, 403-416. [CrossRef]

15. Gao, H.; Birkett, C.; Lettenmaier, D.P. Global monitoring of large reservoir storage from satellite remote sensing. Water Resour. Res. 2012, 48, W09504. [CrossRef]

16. Boergens, E.; Buhl, S.; Dettmering, D.; Klüppelberg, C.; Seitz, F. Combination of multi-mission altimetry data along the Mekong River with spatio-temporal kriging. J. Geod. 2017, 91, 519-534. [CrossRef]

17. Chen, J.; Dowman, I.; Li, S.; Li, Z.; Madden, M.; Mills, J.; Paparoditis, N.; Rottensteiner, F.; Sester, M.; Toth, C.; et al. Information from imagery: ISPRS scientific vision and research agenda. ISPRS J. Photogramm. Remote Sens. 2016, 115, 3-21. [CrossRef]

18. Li, X.; Long, D.; Huang, Q.; Han, P.; Zhao, F.; Wada, Y. High-temporal-resolution water level and storage change data sets for lakes on the Tibetan Plateau during 2000-2017 using multiple altimetric missions and Landsat-derived lake shoreline positions. Earth Syst. Sci. Data 2019, 11, 1603-1627. [CrossRef]

19. Donlon, C.; Berruti, B.; Buongiorno, A.; Ferreira, M.-H.; Féménias, P.; Frerick, J.; Goryl, P.; Klein, U.; Laur, H.; Mavrocordatos, C.; et al. The Global Monitoring for Environment and Security (GMES) Sentinel-3 mission. Remote Sens. Environ. 2012, 120, 37-57. [CrossRef]

20. Song, C.; Huang, B.; Ke, L. Modeling and analysis of lake water storage changes on the Tibetan Plateau using multi-mission satellite data. Remote Sens. Environ. 2013, 135, 25-35. [CrossRef]

21. Wingham, D.J.; Francis, C.R.; Baker, S.; Bouzinac, C.; Brockley, D.; Cullen, R.; de Chateau-Thierry, P.; Laxon, S.W.; Mallow, U.; Mavrocordatos, C.; et al. CryoSat: A mission to determine the fluctuations in Earth's land and marine ice fields. Adv. Space Res. 2006, 37, 841-871. [CrossRef]

22. Goumehei, E.; Tolpekin, V.; Stein, A.; Yan, W. Surface water body detection in polarimetric SAR data using contextual complex wishart classification. Water Resour. Res. 2019, 55, 7047-7059. [CrossRef]

23. Weekley, D.; Li, X. Tracking multidecadal lake water dynamics with Landsat imagery and topography/bathymetry. Water Resour. Res. 2019, 55, 8350-8367. [CrossRef]

24. Showstack, R. Sentinel satellites initiate new era in earth observation. Eos Trans. Am. Geophys. Union 2014, 95, 239-240. [CrossRef]

25. Pekel, J.-F.; Cottam, A.; Gorelick, N.; Belward, A.S. High-resolution mapping of global surface water and its long-term changes. Nature 2016, 540, 418-422. [CrossRef]

26. Pickens, A.H.; Hansen, M.C.; Hancher, M.; Stehman, S.V.; Tyukavina, A.; Potapov, P.; Marroquin, B.; Sherani, Z. Mapping and sampling to characterize global inland water dynamics from 1999 to 2018 with full Landsat time-series. Remote Sens. Environ. 2020, 243, 111792. [CrossRef]

27. Avisse, N.; Tilmant, A.; Müller, M.F.; Zhang, H. Monitoring small reservoirs' storage with satellite remote sensing in inaccessible areas. Hydrol. Earth Syst. Sci. 2017, 21, 6445-6459. [CrossRef] 
28. Busker, T.; de Roo, A.; Gelati, E.; Schwatke, C.; Adamovic, M.; Bisselink, B.; Pekel, J.-F.; Cottam, A. A global lake and reservoir volume analysis using a surface water dataset and satellite altimetry. Hydrol. Earth Syst. Sci. 2019, 23, 669-690. [CrossRef]

29. Bonnema, M.; Sikder, S.; Miao, Y.; Chen, X.; Hossain, F.; Pervin, I.A.; Mahbubur Rahman, S.M.; Lee, H. Understanding satellitebased monthly-to-seasonal reservoir outflow estimation as a function of hydrologic controls. Water Resour. Res. 2016, 52, 4095-4115. [CrossRef]

30. Huang, Q.; Long, D.; Du, M.; Han, Z.; Han, P. Daily continuous river discharge estimation for ungauged basins using a hydrologic model calibrated by satellite altimetry: Implications for the SWOT mission. Water Resour. Res. 2020, 56, e2020WR027309. [CrossRef]

31. Gao, H. Satellite remote sensing of large lakes and reservoirs: From elevation and area to storage. Wiley Interdiscip. Rev. Water 2015, 2, 147-157. [CrossRef]

32. Van Bemmelen, C.W.T.; Mann, M.; de Ridder, M.P.; Rutten, M.M.; van de Giesen, N.C. Determining water reservoir characteristics with global elevation data. Geophys. Res. Lett. 2016, 43, 11-278. [CrossRef]

33. Han, Z.; Long, D.; Huang, Q.; Li, X.; Zhao, F.; Wang, J. Improving reservoir outflow estimation for ungauged basins using satellite observations and a hydrological model. Water Resour. Res. 2020, 56, e2020WR027590. [CrossRef]

34. Eldardiry, H.; Hossain, F. Understanding reservoir operating rules in the transboundary nile river basin using macroscale hydrologic modeling with satellite measurements. J. Hydrometor. 2019, 20, 2253-2269. [CrossRef]

35. Swenson, S.; Wahr, J. Monitoring the water balance of Lake Victoria, East Africa, from space. J. Hydrol. 2009, 370, 163-176. [CrossRef]

36. Muala, E.; Mohamed, Y.A.; Duan, Z.; van der Zaag, P. Estimation of reservoir discharges from lake nasser and roseires reservoir in the Nile Basin using satellite altimetry and imagery data. Remote Sens. 2014, 6, 7522-7545. [CrossRef]

37. Bonnema, M.; Hossain, F. Inferring reservoir operating patterns across the Mekong Basin using only space observations. Water Resour. Res. 2017, 53, 3791-3810. [CrossRef]

38. Madadgar, S.; Moradkhani, H.; Garen, D. Towards improved post-processing of hydrologic forecast ensembles. Hydrol. Process. 2014, 28, 104-122. [CrossRef]

39. Pagano, T.C.; Shrestha, D.L.; Wang, Q.J.; Robertson, D.; Hapuarachchi, P. Ensemble dressing for hydrological applications. Hydrol. Process. 2013, 27, 106-116. [CrossRef]

40. Wang, L.; Huang, C.C.; Pang, J.; Zha, X.; Zhou, Y. Paleofloods recorded by slackwater deposits in the upper reaches of the Hanjiang River valley, middle Yangtze River basin, China. J. Hydrol. 2014, 519, 1249-1256. [CrossRef]

41. Yang, G.; Guo, S.; Liu, P.; Li, L.; Xu, C.-Y. Multiobjective reservoir operating rules based on cascade reservoir input variables selection method. Water Resour. Res. 2017, 53, 3446-3463. [CrossRef]

42. Liu, D.; Guo, S.; Shao, Q.; Liu, P.; Xiong, L.; Wang, L.; Hong, X.; Xu, Y.; Wang, Z. Assessing the effects of adaptation measures on optimal water resources allocation under varied water availability conditions. J. Hydrol. 2018, 556, 759-774. [CrossRef]

43. Dinardo, S.; Fenoglio-Marc, L.; Buchhaupt, C.; Becker, M.; Scharroo, R.; Fernandes, M.J.; Benveniste, J. Coastal SAR and PLRM altimetry in German Bight and West Baltic Sea. Adv. Space Res. 2018, 62, 1371-1404. [CrossRef]

44. Jiang, L.; Nielsen, K.; Andersen, O.B.; Bauer-Gottwein, P. CryoSat-2 radar altimetry for monitoring freshwater resources of China Remote Sens. Environ. 2017, 200, 125-139. [CrossRef]

45. Nielsen, N.; Stenseng, L.; Andersen, O.B.; Villadsen, H.; Knudsen, P. Validation of Cryosat-2 SAR mode based lake levels. Remote Sens. Environ. 2015, 171, 162-170. [CrossRef]

46. Druce, D.; Tong, X.; Lei, X.; Guo, T.; Kittel, C.M.M.; Grogan, K.; Tottrup, C. An optical and SAR based fusion approach for mapping surface water dynamics over mainland China. Remote Sens. 2021, 13, 1663. [CrossRef]

47. Li, H.; Zhang, Y. Regionalising rainfall-runoff modelling for predicting daily runoff: Comparing gridded spatial proximity and gridded integrated similarity approaches against their lumped counterparts. J. Hydrol. 2017, 550, 279-293. [CrossRef]

48. Yang, X.; Magnusson, J.; Huang, S.; Beldring, S.; Xu, C.-Y. Dependence of regionalization methods on the complexity of hydrological models in multiple climatic regions. J. Hydrol. 2020, 582, 124357. [CrossRef]

49. Perrin, C.; Michel, C.; Andréassian, V. Improvement of a parsimonious model for streamflow simulation. J. Hydrol. 2003, 279, 275-289. [CrossRef]

50. Jakeman, A.J.; Littlewood, I.G.; Whitehead, P.G. Computation of the instantaneous unit hydrograph and identifiable component flows with application to two small upland catchments. J. Hydrol. 1990, 117, 275-300. [CrossRef]

51. Chiew, F.H.S.; Peel, M.C.; Western, A.W.; Singh, V.P.; Frevert, D. Application and testing of the simple rainfall-runoff model SIMHYD. In Mathematical Models of Small Watershed Hydrology and Applications; Water Resources PublicationsHighlands: Ranch, CO, USA, 2002; pp. 335-367.

52. Zhao, R.J. Xinanjiang model applied in China. J. Hydrol. 1992, 135, 371-381. [CrossRef]

53. Duan, Q.; Ajami, N.K.; Gao, X.; Sorooshian, S. Multi-models ensemble hydrologic prediction using Bayesian model averaging. Adv. Water Resour. 2007, 30, 1371-1386. [CrossRef]

54. Oudin, L.; Hervieu, F.; Michel, C.; Perrin, C.; Andréassian, V.; Anctil, F.; Loumagne, C. Which potential evapotranspiration input for a lumped rainfall-runoff model? Part 2-Towards a simple and efficient potential evapotranspiration model for rainfall-runoff modelling. J. Hydrol. 2005, 303, 290-306. [CrossRef]

55. Gupta, H.V.; Kling, H.; Yilmaz, K.K.; Martinez, G.F. Decomposition of the mean squared error and NSE performance criteria: Implications for improving hydrological modelling. J. Hydrol. 2009, 377, 80-91. [CrossRef] 
56. Varma, S.; Simon, R. Bias in error estimation when using cross-validation for model selection. BMC Bioinform. 2006, 7, 91-98. [CrossRef]

57. Liu, K.; Tseng, K.; Shum, K.C.; Liu, C.; Kuo, C.; Liu, G.; Jia, Y.; Shang, K. Assessment of the impact of reservoirs in the Upper Mekong River using satellite radar altimetry and remote sensing imageries. Remote Sens. 2016, 8, 367. [CrossRef]

58. Bonnema, M.; Hossain, F. Assessing the potential of the Surface Water and Ocean Topograpghy Mission for reservoir monitoring in the Mekong River basin. Water Resour. Res. 2019, 55, 444-461. [CrossRef]

59. Villadsen, H.; Deng, X.; Andersen, O.B.; Stenseng, L.; Nielsen, K.; Knudsen, P. Improved inland water levels from SAR altimetry using novel empirical and physical retrackers. J. Hydrol. 2016, 537, 234-247. [CrossRef]

60. Biancamaria, S.; Lettenmaier, D.P.; Pavelsky, T.M. The SWOT mission and its capabilities for land hydrology. Surv. Geophys. 2016, 37, 307-337. [CrossRef]

61. Alazard, M.; Leduc, C.; Travi, Y.; Boulet, G.; Salem, A.B. Estimating evaporation in semi-arid areas facing data scarcity: Example of the El Haouareb dam (Merguellil catchment, Central Tunisia). J. Hydrol. Reg. Stud. 2015, 3, 265-284. [CrossRef]

62. Friedrich, K.; Grossman, R.L.; Huntington, J.; Blanken, P.D.; Lenters, J.; Holman, K.D.; Gochis, D.; Livneh, B.; Prairie, J.; Skeie, E.; et al. Reservoir evaporation in the Western United States: Current science, challenges, and future needs. Bull. Am. Meteor. Soc. 2018, 99, 167-187. [CrossRef]

63. Liu, G.; Schwartz, F.W.; Tseng, K.-H.; Shum, C.K. Discharge and water-depth estimates for ungauged rivers: Combining hydrologic, hydraulic and inverse modeling with stage and water-area measurements from satellites. Water Resour. Res. 2015, 51, 6017-6035. [CrossRef]

64. Li, Y.; Grimaldi, S.; Pauwels, V.R.N.; Walker, J.P. Hydrologic model calibration using remotely sensed soil moisture and discharge measurements: The impact on predictions at gauged and ungauged locations. J. Hydrol. 2018, 557, 897-909. [CrossRef]

65. López, P.L.; Sutanudjaja, E.H.; Schellekens, J.; Sterk, G.; Bierkens, M.F.P. Calibration of a large-scale hydrological model using satellite-based soil moisture and evapotranspiration products. Hydrol. Earth Syst. Sci. 2017, 21, 3125-3144. [CrossRef]

66. Kittel, C.M.M.; Nielsen, K.; Tøttrup, C.; Bauer-Gottwein, P. Informing a hydrological model of the Ogooué with multi-mission remote sensing data. Hydrol. Earth Syst. Sci. 2018, 22, 1453-1472. [CrossRef] 